\title{
AGING WORKERS
}

Juhani E IImarinen

\section{CHANGING DEMOGRAPHY}

There are several reasons for the aging of the work force, the main two being the baby boom after the second world war, and the low birth rates which began in the 1980s. In the European Union (EU), the age groups of 50-64 years and 15-24 years both comprised about $25 \%$ of the work force in 1985. By 2005, the "oldest" group will account for $27 \%$ of the work force, while the "youngest" group will account for only $18 \%$. It has been predicted that in 2025 there will be twice as many workers aged 50 years or older as those aged 25 years or younger (fig 1) in the present 15 member states. The work force of the entire EU will attain its oldest age during the next 25 years. The predictions have been based on current mortality and birth rate tables and emigration rates. Although the major increase in the emigration rates of younger generations into the EU may decrease the difference between the "oldest" and "youngest" cohorts, it will not solve the problems of older workers. On the other hand, as the EU is extended, the proportion of older workers will probably increase greatly.

The International Labor Organization (ILO) has estimated that by the year 2025, the proportion of individuals over the age of 55 years will be $32 \%$ in Europe, $30 \%$ in North America, $21 \%$ in Asia, and $17 \%$ in Latin America. The changing demography is a great global challenge, and it will hit the developed countries first. Although the relatively low participation rates of 5064 year olds in the EU labour force somewhat balances the differences between the younger and older generations in work life, the alarming decline of 50-54 year olds in the EU labour force indicates that the fit between aging and work is already critical and appropriate concepts and practices are needed for solutions. The participation rates of age groups 55-59 years and 60-64 years of $60 \%$ and $20 \%$, respectively, show that the majority of the work force leaves work life before a normal retirement age; therefore, it can be concluded that the mandatory retirement age of 65 years is no longer of any importance.

The demographic change, together with low participation rates, is creating a serious problem, which can be described by the age dependency ratio. The number of dependents (those aged 014 years, and 65 years and over) of the working age population (15-64 years) shows that there are currently about 50 dependents for each 100 persons employed. In 2025 the ratio is expected to be 58/100 in the EU. In some countries, such as Finland, the ratio will increase to up to 66/ 100 during the next 25 years. Sweden will have a heavy age dependency ratio $(>55 / 100)$ by 2005-15, and Ireland and Austria will have the lowest ratios (<50/100).

However, the criterion of $0-14$ years and 65 years and over for dependents is not the most

Correspondence to: Professor Juhani Ilmarinen, Finnish Institute of Occupational Health, Department of Physiology, Laajaniityntie 1, FIN-01620 Vantaa, Finland

juhani.ilmarinen@occuphealth.fi relevant for the current situation because most adolescents 15 years and older are still in school or in some form of educational process, and most people 60 years and older are already out of work life. When using 0-19 years and 60 years and older as the criterion for dependents, a completely different level of age dependency ratio can be calculated. For example, in the EU there will be more than 80 dependents for each 100 employed persons in 2005-15. Several 


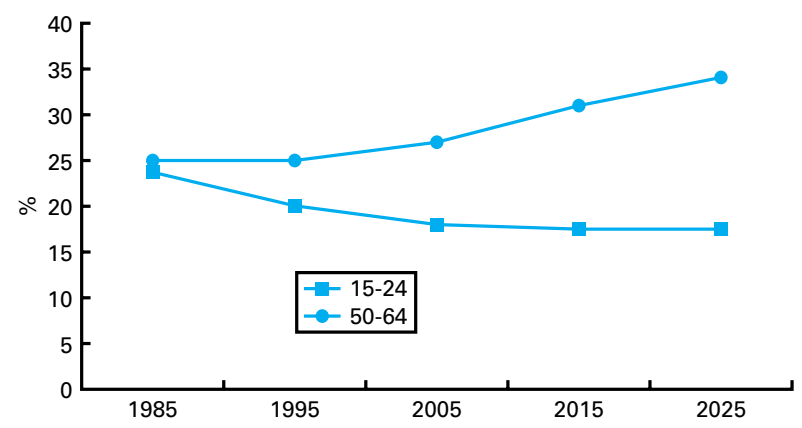

Figure 1 Expected proportion of two different age groups of workers (15-24 years, and 50-64 years) from the entire workforce (15-66 years) in the EU over the next 25 years.

countries, such Finland, Sweden, France, Greece, Denmark, and Belgium, will even exceed the ratio of $90 / 100$ by the year $2015 .^{2}$

The main conclusions that can be drawn from these EU statistics are summarised in the box below.

A general conclusion is that the employment rate of aging workers ( 55 years and older) must be increased greatly. The key question is how? Before possible concepts and actions for solutions are introduced, some essential changes in human resources during aging should be briefly illustrated.

\section{Physical and mental changes that accompany aging}

Much scientific data and excellent textbooks describe the physical, mental, and social aging processes. ${ }^{3}$ The major evidence on the effect of the aging processes has been generated, however, by gerontological research, which has often focused on the later decades of life. In the field of occupational health there has been a growing interest since the 1980s in research on the changes in human resources in relation to work demands and aging. An increasing amount of data show that the effects of aging on work life should be taken into consideration more often and efforts should be made to increase the employment rate of aging workers. ${ }^{4-8}$

\section{Physical work capacity}

Changes in physical work capacity have often concentrated on the cardiovascular and musculoskeletal systems, body structure, and some important sensory systems. The maximal oxygen consumption $\left(\dot{\mathrm{V}}_{2} \mathrm{max}\right)$ in absolute $(1 / \mathrm{min})$ and relative $(\mathrm{ml} / \mathrm{min} / \mathrm{kg})$ terms shows a clear and linear decline with age among both men and women (fig 2). The decline of $\dot{\mathrm{V}}_{2}$ max starts after full physical maturity has been reached, at the latest after the age of 30 years. ${ }^{9}$ However, longitudinal studies have shown that changes in $\dot{\mathrm{V}}_{2}$ max can be much larger at the individual level than expected. ${ }^{10}$ In four

\section{Box 1: Main conclusions from EU statistics on aging}

- There will be more potential aging (50 years and over) workers in the work force than ever before

- Workers aged 50 years and older will comprise the largest proportion (> 30\%) of the work force during the next 25 years

- There will be fewer younger workers (25 years and younger) in the work force than ever before

- The work force participation rates of workers 55 years of age and over is declining greatly

- The age dependency ratios will increase greatly during the next $15-25$ years

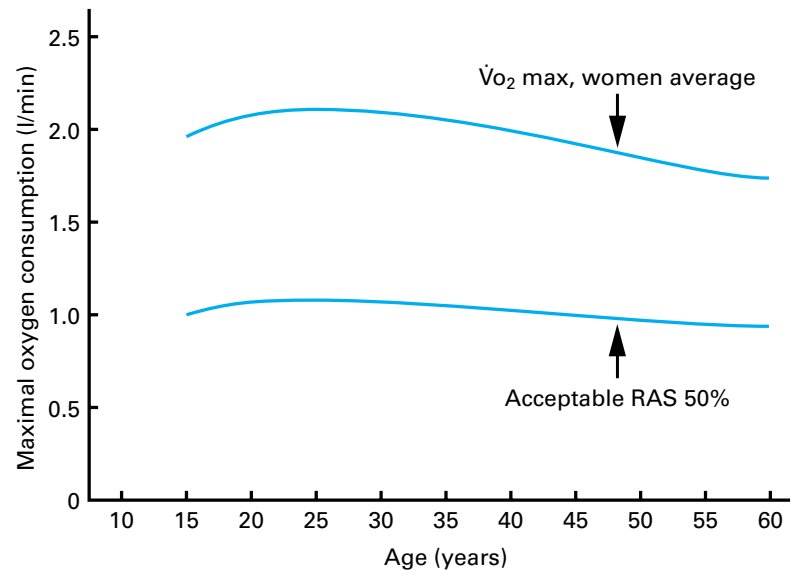

Figure 2 Change in maximal oxygen consumption ( $\left.\dot{\mathrm{V}}_{2} \max \right)$ in women with aging. RAS $50 \%=50 \%$ of $\dot{\mathrm{V}}_{2} \max$.

years the $\dot{\mathrm{V}}_{2} \max$ can decrease or increase by about $25 \%$ in men and women after the age of 45 years. These changes are strongly dependent on the aerobic exercise, or lack of it, during the preceding years; therefore, different levels of exercise behaviour can have remarkable effects on $\dot{\mathrm{V}}_{2} \max$. It is therefore understandable that the level of $\dot{\mathrm{V}}_{2} \max$ can become critical in physically demanding work much earlier than expected. Women aged 45 years with an average $\dot{\mathrm{V}}_{2} \max$ of $2.0 \mathrm{l} / \mathrm{min}$ can work in jobs in which the $\dot{\mathrm{V}}_{\mathrm{O}_{2}} \max$ does not exceed $1.0 \mathrm{l} / \mathrm{min}$; international recommendations say that physical work should not require more than $50 \%$ of a worker's $\dot{\mathrm{V}}_{2}$ max. ${ }^{11}$ If an unfit woman 40 years of age has a $\dot{\mathrm{V}}_{2} \max$ of only $1.5 \mathrm{l} / \mathrm{min}$, she is allowed to consume up to 0.751 of oxygen a minute without causing overload. In practice, this level of cardiorespiratory capacity would correspond to work in a sitting position or light work while standing. Moving from one place to another or, for example, lifting and carrying loads, will easily exceed oxygen consumption of $1.0 \mathrm{1} / \mathrm{min}$ and cause overload. A low age related cardiorespiratory capacity means that the majority of auxiliary female jobs, such as cleaning, nursing, and homecare work, can overload workers and have negative health consequences in the long run. Therefore, it is very important, especially, among the aging female population, that:

- the physical work load of jobs should be decreased with advancing age;

- there should be regular exercise to keep the cardiorespiratory capacity to at least the age related average.

Changes in musculoskeletal capacity can also be pronounced after the age of 45-50 years. In follow up studies both the maximal isometric trunk extension and flexion strength of male workers in physically and mentally demanding jobs decreased by $40-50 \%$ during a 10 year period. The decrease was 4-5 times greater than in cross sectional studies. ${ }^{12}$ An important finding was that the decline was similar for blue and white collar workers. This evidence indicates: (1) that the physical nature of today's work does not prevent a decline in musculoskeletal function; and (2) that workers involved in physically demanding jobs need positive physical exercise to stay at an average level of age related fitness. For aging blue collar male workers the recommendation is the same as for female workers, namely, physical work load should decline with advancing age. The decline of physical capacities can be compensated by regular exercise, but the ethical question is to what extent it can be required of blue collar workers? A more balanced and accepted concept for a solution would be: 
- for the worker to maintain a normal age related average fitness level;

- and for the physical load of work to decrease according to the normal age decline in physical capacity (20-25\%) during the ages of 45-65 years.

Generally, the changes in physical capacity in relation to aging are often difficult to distinguish because, for example, work and living habits can accelerate or slow down such changes. Therefore individual differences are enormous among aging workers. Regular physical exercise can keep physical capacity nearly unchanged between 45-65 years, and a lack of appropriate exercise can make a 45 year old worker less fit than his or her active colleague aged 65 years. Unfortunately, only a small proportion of the aging working population is physically active during leisure time, and the figures are lowest for blue collar workers. The minimal amount of exercise needed daily to prevent a premature decline in physical capacity and musculoskeletal or cardiovascular disorders is still an open question, although excellent reviews are available. ${ }^{13}$

\section{Mental functional capacity}

Mental functional capacity is often defined as the ability to perform different tasks that require intellectual and other kinds of mental effort. Cognitive functions, such as perception, memory, learning, thinking, and the use of language have been the primary targets of research. Another central area of mental capacity is the relation between the individual and the outside world-for example, self concept, self value, perceived competency, and control of life. The newest component is that of metacognition, which involves the evaluation of a person's own cognitive functioning. Mental health, physical well being and, for example, attitudes towards one's own aging are closely related to mental capacity.

From the point of view of work life the most important changes in mental functions are related to the weakening of precision and the speed of perception. The changes concern the entire human system for processing information: (1) the sensoriperceptive system that is responsible for receiving information through the senses; (2) the cognitive system that processes the data from the senses and memory system; and (3) the motor system that is responsible for the realisation of decided functions. Apparently the functioning of all three systems slows with age.

The actual functions of information processing change very little in the course of one's career. Moreover, some cognitive functions, such as control of use of language or the ability to process complex problems in insecure situations, improve with age. In most work tasks, speed and precision can be substituted by the high motivation of aging workers and the experience and wisdom they have assembled throughout their work life. Even though the speed of learning may slow with age, the actual learning process is not dependent on a person's age. Strong motivation to learn can also compensate for the slower learning speed.

According to the literature, some mental characteristics can also strengthen with age. ${ }^{14}{ }^{15}$ These factors can be summarised by a delineator of 'aging and mental growth' (see box).

Experience, work performance, and aging together form interesting interactions. The positive effects of job experience can be directed towards basic cognitive processes or job performance. ${ }^{16}$ If job experience primarily improves or maintains cognitive skills, the positive connection between job experience and performance remains weaker. If, instead, job experience directly improves or maintains job performance, the link between job experience and cognitive

Box 2: Aging and mental growth
Wisdom
Sharp wittedness
Ability to deliberate
Ability to reason
Ability to comprehend the
whole

skills remains undeveloped. Both of these mechanisms of job experience are possible and can explain why job performance does not weaken with age (fig 3). A more creative use of job experience can significantly improve the coping of aging workers in work life. The job performance of older workers has been shown to be at least as productive as that of younger workers. The results between age groups have been found to be the same in skill demanding and speed demanding jobs. ${ }^{17}$

Changes in physical and mental functions during working age show both similar and different trends. Interestingly, the weakening of physical functions does not hinder improvement in some mental functions. This contrast is even more surprising because the prevalence and incident rates of diseases increase greatly with age. Perhaps the deterioration of health acts as a catalyst for mental growth. On the basis of the changes found in physical and mental functions during aging, one general conclusion can be drawn: because a large proportion of workers is becoming physically weaker but mentally stronger with advancing age, their work life should be less physically demanding and include more of the mental characteristics that improve during their career.

\section{Work ability and employability}

In the late 1990s a new concept on work ability was introduced by the Finnish Institute of Occupational Health. ${ }^{2}$ It was partly based on the results of an 11 year follow up of over 6500 blue and white collar workers. ${ }^{18}$ The concept emphasises that individual work ability is a process of human resources in relation to work. Human resources can be described by (1) health and functional capacities (physical, mental, social), (2) education and competence, (3) values and attitudes, and (4) motivation. When this comprehensive set of individual factors is related to (5) work demands (physical, mental), (6) work community and management, and (7) work environment, the outcome can be called the individual work ability (fig 4 ). The work ability concept is a dynamic process that changes greatly for several reasons throughout an individual's work life. One of the main factors inducing change is aging and its effects on human resources. The other large source of change aging workers must face is the change in the nature of work. Work organisations, work methods and tools, and also work loads are changing today faster than human resources can easily adapt. For example, the implementation of new technology has often caused more problems than positive challenges for aging workers. The dynamics needed to fit human resources to the new work demands have often been left undeveloped and have therefore caused the displacement of many workers over the age of 55 years from the labour market. It has been often incorrectly argued that their competency is no longer sufficient and their experiences are less valid. However, the major reason has often been the uncontrolled changes that have occurred in work and the lack of adjustments urgently needed for fitting their resources to the new work demands. 


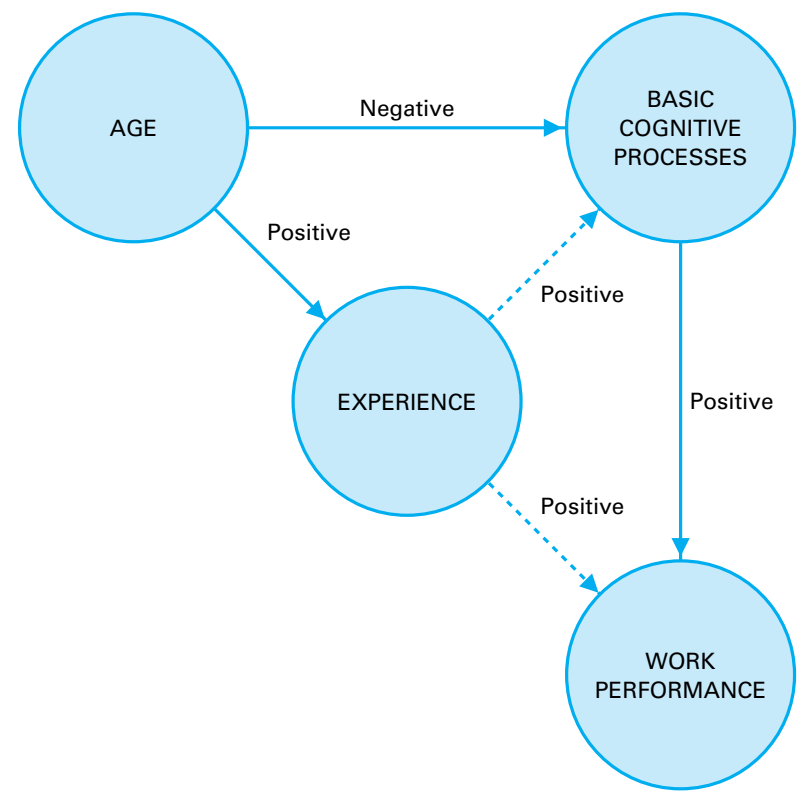

Figure 3 Interrelation between age, experience, and work performance. ${ }^{16}$

The common need to blame the worker should be redirected towards those responsible for planning and carrying out changes at work, who overlook the need for adjustments. As soon as the shortage of manpower becomes acute, the attitudes towards aging workers will change and adjustments will be demanded for practical solutions. Therefore, the focus of research and actions taken in the late 1990s has been: (1) to identify the key issues of the adjustments needed; and (2) to develop and test the processes that can make work life a success for aging workers.

Employability is a new term describing the actions needed to improve the rate of employment. It includes employment, education and exit policies, a large variety of social and health services, and also, for example, the general prevention of age discrimination. The concept of employability is still developing but it can currently be described mainly by powerful characteristics and infrastructures needed at the level of society for better employment of all age groups. However, the belief that employability alone can solve the problems of employment is misleading, at least for aging workers. The modern concept and the latest experiences show that there are two main processes that affect the

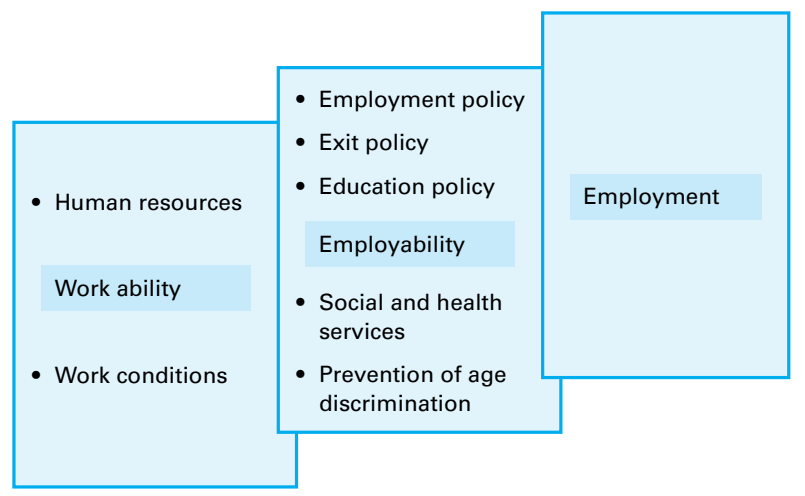

Figure 5 Relation between work ability, employability, and employment.

employment rate of aging workers, one being the promotion of work ability, and the other being the development of employability (fig 5).

The promotion of work ability is a basic process that is needed before the features of employability can be fully utilised. The content of work ability was introduced in fig 4, and it emphasises that action is needed at both the worksite and the individual level. The most effective combination is the integration of the adjustments needed in the work community and work environment, as in aspects of individual health and functional capacities and professional competence. The results of follow up studies and experiences in the 1990s show, for example, that the following single actions can improve work ability during aging:

- training of supervisors for age management

- implementation of age ergonomics

- worksite exercise programmes

- tailored training in new technology.

The results are better if several actions are integrated. The consequences of improved work ability can be measured as better work productivity and quality of work and the better well being and life quality of aging workers. The long term effects of actions have been measured as a better third age quality (fig 6). The basic concept for the promotion of work ability is the same for all age groups. However, the adjustments needed and single actions to be carried out are age dependent. Therefore tailoring is needed that is based on the effects of aging on work ability. ${ }^{19}$ Examples in private, municipal, and governmental sectors are available, for example, in the report of the FinnAge Action Programme. ${ }^{20}$

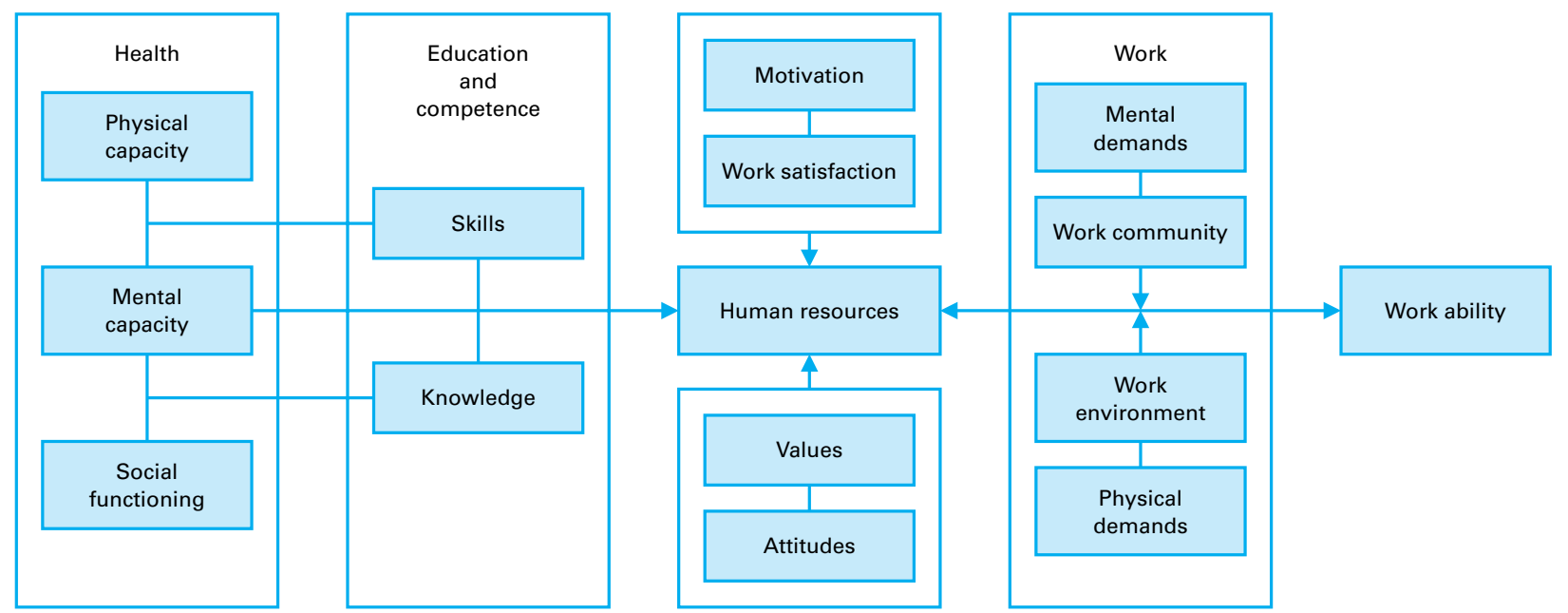

Figure 4 New concept of work ability, emphasising that individual work ability is a process of human resources in relation to work. 
THE INDIVIDUAL

(functional capacities, health)

WORK ENVIRONMENT (ergonomics, hygiene, safety)

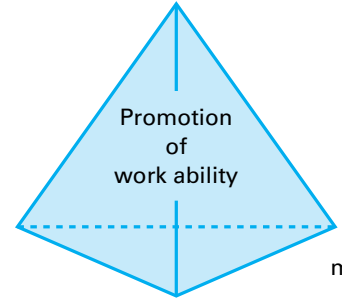

ORGANISATION LEADERSHIP (developmental, psychosocial and

Professional

competence
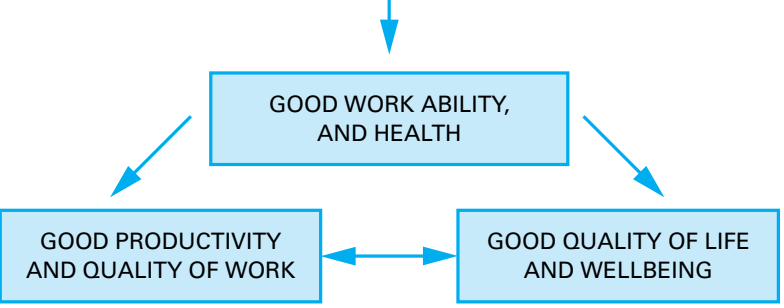

GOOD RETIREMENT ABILITY MEANINGFUL, SUCCESSFUL, AND PRODUCTIVE

"THIRD AGE"

Figure 6 Schema showing consequences of good work ability.
The promotion of work ability creates the base for the processes of employability. Together they can be powerful tools for improving employment at all ages, especially for aging workers.

\section{Aging and work: the role of the individual, the organisation, and society}

Aging and work can be comprehended as a whole when the roles and responsibilities of the individual, the organisation/ enterprise, and society are taken into consideration. An orientation matrix, shown in fig 7, has been constructed describing the relations between the problems, solutions, and goals of the individual worker, the enterprise or organisation, and society. The nine fields of the matrix can be read vertically, horizontally or diagonally.

The vertical level stresses the possibility for these groups to share the responsibility of keeping aging workers in work life, and therefore the measures needed to solve the problems can be better planned and more focused. On the horizontal level the dimensions of recognising problems, choosing solutions, and setting goals depict the fact that solutions are available and objectives can be brought into focus from the point of view of the individual, the enterprise or society. The horizontal level emphasises action. The diagonal arrows between the worker and enterprise dimensions depict the strong connection between the two.

The key words of the matrix have been chosen on the basis of data from a large set of studies from the 1990s. The words are not arranged according to their significance and they are mentioned only once. The better the goals of the individual and the enterprise are met, the better society's objectives and results succeed (depicted in the lower right hand corner of the matrix). The company is the most important, however,
PROBLEMS/POSSIBILITIES

INDIVIDUAL

INDIVIDUAL

ENTERPRISE

- functional capacity

- health

- competence

- work motivation

- work ability

- work exhaustion

- unemployment
MEANS/SOLUTIONS

\begin{tabular}{|c|c|}
\hline $\begin{array}{l}\text { - promotion of physical, mental } \\
\text { and social resources } \\
\text { - improving health } \\
\text { - developing competence } \\
\text { - coping with changes } \\
\text { - participating }\end{array}$ & $\begin{array}{l}\text { - better functional capacities } \\
\text { - better health } \\
\text { - better competence } \\
\text { - better work ability } \\
\text { - less exhaustion } \\
\text { - lower unemployment risk } \\
\text { - better quality of life }\end{array}$ \\
\hline 4 & 4 \\
\hline $\begin{array}{l}\text { - age management } \\
\text { - individual solutions } \\
\text { - cooperation between age groups } \\
\text { - age ergonomics } \\
\text { - work-rest schedules } \\
\text { - flexible working times } \\
\text { - part time work } \\
\text { - tailored competence-training }\end{array}$ & $\begin{array}{l}\text { - better total productivity } \\
\text { - better competitiveness } \\
\text { - fewer sick leaves } \\
\text { - better management } \\
\text { - competent manpower } \\
\text { - better image } \\
\text { - lower work disability costs }\end{array}$ \\
\hline & $\downarrow$ \\
\hline $\begin{array}{l}\text { - changing attitudes } \\
\text { - preventing age discrimination } \\
\text { improving age conscious work } \\
\text { policy } \\
\text { - changing age conscious exit } \\
\text { policy }\end{array}$ & $\begin{array}{l}\text { - less age discrimination } \\
\text { - later retirement } \\
\text { - lower unemployment costs } \\
\text { - lower health care costs } \\
\text { - better national economy } \\
\text { - higher welfare }\end{array}$ \\
\hline
\end{tabular}

Figure 7 Orientation matrix: aging and work. 
because it is responsible for the realisation of the individual's participation in work. A European portfolio of good practice has shown that companies in different member states of the EU have used similar basic solutions to combat age barriers in employment. ${ }^{21}$ Scientifically well evaluated practices are needed, and the adoption of the processes of these leading companies should be widely used.

The main message of the matrix is that, despite its complexity, the situation as a whole can be comprehended and controlled, and the change in the age structure can become a fruitful challenge in enterprises and societies all over the world. Useful international recommendations for this process are available. ${ }^{22}$

\begin{tabular}{|c|c|}
\hline \multicolumn{2}{|c|}{ Box 3: Definitions of key terms in this article } \\
\hline $\begin{array}{l}\text { Human } \\
\text { resources }\end{array}$ & $\begin{array}{l}\text { - a combination of health, physical } \\
\text { capacity, mental capacity, social } \\
\text { functioning, education and competence, } \\
\text { motivation, attitudes and values }\end{array}$ \\
\hline Dork ability & $\begin{array}{l}\text { - human resources related to physical, } \\
\text { mental, and social demands of work, work } \\
\text { community and management, organisational } \\
\text { culture, and work environment }\end{array}$ \\
\hline D Employability & $\begin{array}{l}\text { - work ability related to society level } \\
\text { characteristics, such as employment, } \\
\text { education and exit policies, } \\
\text { social and health services including } \\
\text { occupational health services and } \\
\text { rehabilitation, and other } \\
\text { preventive measures such as prevention of } \\
\text { age discrimination }\end{array}$ \\
\hline $\begin{array}{l}\text { The content o } \\
\text { cate that hum } \\
\text { form a contin }\end{array}$ & $\begin{array}{l}\text { y terms are partly overlapping, which indi- } \\
\text { resources, work ability, and employability } \\
\text { s process together for employment. }\end{array}$ \\
\hline
\end{tabular}

\section{References}

1 IImarinen J, Tuomi K, Klockars M. Changes in the work ability of active employees over an 11-year period. Scand $J$ Work Environ Health 1997;23 (suppl 1):49-57.

2 IImarinen J. Ageing workers in the European Union-status and promotion of work ability, employability and employment. Helsinki: Finnish Institute of Occupational Health, Ministry of Social Affaire and Health, Ministry of Labour, 1999:274 pages.

- This book consists of statistics on aging in Europe as well as various modern aspects of aging workers: health, functional capacities, education and training, work environment, work demands, and the new work ability concept. A comparison of the $15 \mathrm{EU}$ member states is given. The second part of the book introduces the promotion of aging workers' work ability and employability (www. occuphealth.fi/julkaisu/eng/order.htm)

3 Birren JE, ed. Handbooks of aging. New York: Academic Press, 1990.

4 Goedhard WJA, ed. Aging and work 4. The Hague: Pasmans, 2000.

5 Snel J, Cremer R, eds. Work and aging: a European perspective. London and Bristol: Taylor and Francis, 1994.

6 Kumashiro M, ed. The paths to productive ageing. London and Bristol: Taylor and Francis, 1995

7 Kilbom Å, Westerholm P, Hallsten L, et al, eds. Work after 45? Volume I and II. Arbete och Hälsa 29, Arbetslivsinstitutet, Solna 1997.

8 Winn FJ, Nielsen J, Fallentin N, et al, eds. Second International Conference on Aging and Work. Experimental aging research. Special issue. Philadelphia: Taylor \& Francis 1999:4, 25.

- This special issue introduces the latest research on aging and work. The following issues of aging are addressed: mental and physical factors, work design and management, training and education, attitudes, structural impediments, prevention of early exit, nationa and governmental policies. The articles describe the research activities in 16 countries showing similarities in problems and differences in problem solving.
9 Shwartz E, Reibold RC. Aerobic fitness norms for males and females aged 6 to 75 years: a review. Aviation, Space Environmental Med 1990;61:1990:3-11.

10 IImarinen J, Louhevaara V, Korhonen O, et al. Changes in maximal cardiorespiratory capacity among aging municipal employees. Scand $J$ Work Environ Health 1991;17 (suppl 1):99-109.

11 IImarinen J. Job design for the aged with regard to decline in their maximal aerobic capacity. Part I-guidelines for the practitioner. Part II-The scientific base for the guide. Int J Ind Ergon 1992;10: 53-77

12 Nygård $\mathrm{CH}$, Pohjonen $\mathrm{T}$, Ilmarinen J. Muscular strength of ageing employees over an 11-year period. In: IImarinen J, Louhevaara V, eds. FinnAge-Respect for the ageing. People and work, Research reports 26. Helsinki: Finnish Institute of Occupational Health, 1999, 240-9

13 US Department of Health and Human Services. Physical activity and health. A report of the Surgeon General. Atlanta, Georgia: US Department of Health and Human Services, Centers for Disease Control and Prevention, National Center for Chronic Disease Prevention and Health Promotion, 1996.

14 Baltes PB, Smith J. Toward a psychology of wisdom. In: Stenberg RJ, ed. Wisdom: its nature, origin and development. New York: Cambridge University Press, 1990:87-120.

15 Schaie KW. The course of adult intellectual development. American Psychologist 1994;38:239-313.

16 Salthouse TA. Implications of adult age differences in cognition for work performance. In: Kilbom Å, Westerholm P, Hallsten L, eds. Work after 45? Volume 1, Arbete och Hälsa. Arbetslivsinstitutet, Solna 1997:15-28.

- This article introduces a variety of experimental studies on cognitive aging and work performance. It discusses critically the conflicting results of laboratory and field studies and emphasises the role of work experience both on cognitive functions and work performance.

17 Spirduso WW. Job performance of the older worker. In: Spirduso WW, ed. Physical dimensions of aging. Chapter 13. Champaign, Illinois: Human Kinetics, 1995:367-87.

- This book, and especially chapter 13 , corrects several false myths about aging. It summarises the changes needed at worksites according to the changes of aging in different body functions-a practical list of ergonomic adjustments is given. The chapter focuses also on productivity and aging, indicating, for example, that in both skill demanding and speed demanding jobs the productivity of older workers is better than that of younger workers.

18 Tuomi K, ed. Eleven-year-follow-up of aging workers. Scand J Work Environ Health 1997;23 (suppl 1).

- This supplement introduces the results of longitudinal studies of aging workers in physically, mixed, and mentally demanding jobs. The age related changes in health, stress symptoms, lifestyle, work demands, and work ability are shown. The results of a regression analysis showed which factors improved or caused a deterioration in the work ability of aging workers in 11 years.

19 IImarinen J, Rantanen J. Promotion of work ability during aging. Am J Indust Med, 1999;suppl 1:21-3.

20 IImarinen J, Louhevaara V, eds. FinnAge-Respect for the ageing: action programme to promote the health, work ability and well-being of ageing workers, 1990-1996. People and work, research reports 26. Helsinki: Finnish Institute of Occupational Health, 1999.

- This book summarises the results and experiences of a large research programme focused on aging workers. More than $\mathbf{2 0}$ projects in the private, municipal, and governmental sectors introduce intervention and developmental approaches and their effects on health, functional capacities, work demands, and work ability. The studies on attitudes toward aging and work show the "pushing factors" increasing the risks of early exit, as well as the "pulling factors" keeping older people at work. The different concepts for solutions are given (www. occuphealth.fi/julkaisu/eng/ order.htm).

21 Walker A, Taylor P, eds. Combating age barriers in employment: a European portfolio of good practice. Luxembourg: European Foundation for the Development of Living and Working Conditions, Office for Official Publications of the European Communities, 1998.

22 Work Health Organization. Aging and working capacity. Report of a WHO study group. WHO technical report series 835 . Geneva: WHO, 1993. 


\section{QUESTIONS (See answers on p 459)}

(1) Who is an aging worker from the occupational health point of view?

(a) Everybody in the work force aged 15-64 years

(b) Everybody who has major problems in health and functional capacities

(c) Everybody who has major age related changes in health and functional capacities relevant to work

(d) Everybody who is 45 years and older

(e) Everybody who is 55 years and older

(f) The definition of an aging worker is very individual and cannot be fixed at any particular chronological age

(2) What are the consequences of the work force aging?

(a) There will be more aging $(50+)$ than younger $(<25)$ workers in the work force during 2005-25 in the European Union

(b) The mean age of workers is rising over 45 years in the majority of companies and work organisations in the near future

(c) The participation rates of aging workers in the work force will fall if appropriate adjustments at work are not carried out

(d) The age dependency ratios will increase dramatically during the next decades

(e) The work organisations will change their recruiting policies by trying to hire younger workers

(f) Age discrimination can increase

(3) How can the age related changes in physical work capacity be characterised?

(a) There are no major changes in physical work capacity during aging

(b) The maximal oxygen consumption starts to decline at the latest after 30 years of age

(c) The cardiorespiratory capacity changes significantly during aging, mainly due to the aerobic exercise performed

(d) Isometric trunk extension and flexion strength does not change significantly among blue collar workers

(e) Physical work does not have a training effect on musculoskeletal capacity, similar to muscle training

(f) The physical work load of aging workers must be decreased, especially for aging females

(4) How can the age related changes in mental work capacity be characterised? (a) There are no major changes in mental work capacity during aging

(b) The precision and speed of perception weakens during aging

(c) Processing of information slows with age

(d) Several cognitive and other functions improve with age and mental growth is typical for aging workers

(e) Work experience can compensate for the negative changes of basic cognitive functions

(f) Aging workers cannot learn new skills

(5) How can the modern concept of work ability for aging workers be characterised?

(a) Work ability is a synonym for human resources

(b) Work ability describes the relation between human resources and work

(c) Health and functional capacities form the base for work ability

(d) The problem with work ability during aging is the lack of sufficient human resources

(e) Work loads and organisations are changing faster than human resources

(f) Work ability is a synonym for employability

(6) How can work ability be promoted among aging workers?

(a) No single action is sufficient for work ability promotion but an integration of several measures both at the work site and the individual level is required

(b) Training of supervisors for age management and implementation of age ergonomics are key issues in work sites

(c) Tailoring training in new technology solves all the personal problems of aging workers

(d) Health promoting life styles, such as regular exercise and healthier eating habits, are not important for aging workers

(e) Promotion of work ability is the same for all age groups

(f) Promotion of work ability improves the productivity, well being, and quality of the third age

(g) Aging of the work force is a great challenge if all partners, individuals, enterprises, and societies take care of their responsibilities

\section{Rejected manuscripts}

Authors whose submitted articles are rejected will be advised of the decision and one copy of the article, together with any reviewer's comments, will be returned to them. The
Fournal will destroy remaining copies of the article but correspondence and reviewers' comments will be kept. 